\title{
A gestão de recursos humanos em uma instituição pública brasileira de ciência e tecnologia em saúde: o caso Fiocruz*
}

\author{
Márcio Luiz Braga Corrêa de Mello** \\ Antenor Amâncio Filho***
}

SumÁrio: 1. Introdução; 2. As exigências do trabalho em saúde; 3. Sobre as competências na saúde; 4. Do planejamento à gestão estratégica de recursos humanos; 5. O caso Fiocruz; 6. Resultados e discussão; 7. Considerações finais.

Summary: 1 . Introduction; 2 . The demands of healthcare; 3 . On healthcare competences; 4. From planning to human resources strategic management; 5 . The Fiocruz case; 6. Results and discussion; 7. Final remarks.

Palavras-chave: administração de recursos humanos; planejamento estratégico; inovação organizacional; academias e institutos; administração pública.

KEY WORDS: human resources management; strategic planning; organizational innovation; academies and institutes; public administration.

A partir da década de 1970, a crise do padrão de acumulação capitalista firmado no binômio taylorismo-fordismo levou à sua substituição por formas produtivas flexibilizadas e desregulamentadas. Para enfrentar os novos desafios e garantir sua sobrevivência, as empresas passaram a investir em modernas tecnologias e adotaram concepções organizacionais com ênfase na formação e na gestão de recursos humanos, com o objetivo de atender aos requisitos do processo de trabalho. Este artigo relata a experiência da Fundação Oswaldo Cruz na perspectiva da mudança, fazendo uma abordagem crítica da gestão de recursos humanos em uma instituição

\footnotetext{
* Artigo recebido em dez. 2007 e aceito em mar. 2009.

** Mestre em gestão de saúde pública. Tecnologista em Saúde Pública do Instituto Oswaldo Cruz, da Fundação Oswaldo Cruz, professor da Faetec da Secretaria de Ciência e Tecnologia do Estado do Rio de Janeiro. Endereço: Av. Brasil, 4365, Pavilhão Herman Lentz (Farmanguinhos), sala 1 — Manguinhos - CEP 21045-900, Rio de Janeiro, RJ, Brasil. E-mail: mello@fiocruz.br.

*** Doutor em educação. Pesquisador da Escola Nacional de Saúde Pública Sergio Arouca, da Fundação Oswaldo Cruz. Endereço: Av. Brasil, 4365, DAPS/Escola Nacional de Saúde Pública Manguinhos - CEP 21045-900, Rio de Janeiro, RJ, Brasil. E-mail: amancio@ensp.fiocruz.br.
} 
pública de ciência e tecnologia em saúde, órgão de referência do Ministério da Saúde que ocupa posição estratégica no Sistema Único de Saúde e na formulação da política nacional de ciência e tecnologia em saúde. $\mathrm{O}$ artigo destaca as propostas de inovação em consonância com os princípios da Carta Iberoamericana de Qualidade na Gestão Pública e com os critérios do Modelo Iberoamericano de Excelência em Gestão, visando contribuir para aprimorar a gestão de recursos humanos na Fiocruz, na premissa de que a maior qualificação do corpo de profissionais permitirá que a instituição amplie sua atuação e capacidade de melhorar a saúde da população.

The management of human resources in a public institution of science and technology in health: the Fiocruz case

Since de seventies, the crisis of the capitalist standard of accumulation based on the Taylorist/Fordist binomial caused its substitution by flexible and deregulated production forms. In order to face the new challenges and to guarantee their survival, companies have invested in modern technologies adopted organizational concepts with emphasis in the development and management of human resources, so as to answer the requirements of the new working processes. This article discusses the case of the Oswaldo Cruz Foundation, from the perspective of change, with a critical approach to the management of human resources in a public institution of science and technology in health, which is a reference for the Brazilian Health Ministry and has a strategic position in the Unified Health System. The article is a contribution to the improvement of human resources management at Fiocruz, considering that a higher qualification of the staff will expand the institution's area of activity as well as its capabilities to improve the health of the Brazilian people.

\section{Introdução}

Observam-se, atualmente, grandes transformações em várias áreas da nossa vida, que se processam de maneira intensa e acelerada, geralmente associadas ao desenvolvimento tecnológico. A difusão dessas transformações por todos os setores da sociedade trouxe consequências ao desenvolvimento social e econômico e, por isso, a capacidade de gerar e absorver inovações vem sendo crucial para um país se tornar competitivo no mundo globalizado, mediante investimentos em áreas estratégicas como educação, pesquisa e desenvolvimento tecnológico, bem como é vital assumir uma concepção renovada e revitalizada da gestão do setor público.

Em nosso país, as instituições de pesquisa têm procurado assumir um papel fundamental nesse processo, implementando estruturas e formas de gestão que criem condições de estabelecer ligação mais próxima com o setor produtivo e assim responder, mais efetivamente, por inovações tecnológicas de relevância social. 
Pode-se dizer também que as transformações empreendidas no país a partir dos anos 1990 impactaram de forma decisiva a organização das atividades de pesquisa científica, influenciaram os processos de desenvolvimento tecnológico e afetaram o sistema educacional e o setor público, com consequências para o campo das inovações tecnológicas, promovendo mudanças significativas nas esferas econômica, social e cultural.

No Brasil, no que diz respeito ao campo da saúde, a Fundação Oswaldo Cruz, na qualidade de instituição de ciência e tecnologia e de suporte ao Ministério da Saúde e ao Sistema Único de Saúde, vem fortalecendo o seu compromisso social ao atuar de modo incisivo na construção de políticas públicas que atendam ao ideário, pautando sua trajetória histórica no fortalecimento de atividades voltadas para o campo da saúde pública, contribuindo para a melhoria das condições e, consequentemente, da qualidade de vida da população.

Cabe destacar que, com as transformações decorrentes da crise mundial verificada nos anos 1980 e com a redemocratização do Brasil, ganhou fôlego o Movimento da Reforma Sanitária, que aglutinou forças políticas progressistas em torno da luta pela universalização do acesso aos serviços de saúde e pelo reconhecimento desta como "direito de todos e dever do Estado". Esse movimento incentivou um amplo debate nacional em torno de questões ligadas à saúde, culminando na formulação e no estabelecimento dos princípios e das diretrizes norteadores das ações e serviços de saúde a serem ofertados à população, consubstanciando um Sistema Único de Saúde (SUS) constitucionalmente afirmado. A essência da concepção do SUS é assegurar a todos os brasileiros o direito à saúde, atendendo aos princípios da universalidade, da equidade e da integralidade e às diretrizes operacionais de descentralização da gestão, com ênfase na estadualização e na municipalização, permitindo maior qualidade, rapidez e eficiência nas respostas às demandas da sociedade.

Nessa perspectiva, criar e implementar ações que permitam a criação de estratégias de formação e de gestão de recursos humanos para o SUS inclui a previsão de medidas direcionadas para processos educacionais que permitam ao trabalhador conhecer as necessidades e dominar os novos requerimentos que o mundo do trabalho apresenta.

Este artigo relata a experiência realizada para avaliar a gestão de recursos humanos na Fundação Oswaldo Cruz pela ótica da incorporação dos trabalhadores e do ambiente complexo que conforma uma instituição de ciência e tecnologia, à luz dos novos conceitos e exigências do mundo do trabalho, como forma de contribuir para o fortalecimento das múltiplas ações levadas a termo pela instituição. 


\section{As exigências do trabalho em saúde}

Os requerimentos de recursos humanos estão determinados pela existência de uma gestão pautada por padrões de qualidade, eficiência, eficácia e efetividade, ditados pela dinâmica dos processos de pesquisa, desenvolvimento tecnológico e inovação, em um mundo cada vez mais dinâmico e competitivo:

no contexto de incessantes transformações do mundo corporativo, o maior desafio da área de recursos humanos tem sido integrar as organizações e as pessoas numa única direção - a que produza os melhores resultados empresariais e que ao mesmo tempo satisfaça os anseios de crescimento e valorização, tanto profissional quanto humana, de cada indivíduo.[...] Como consequência, as políticas, práticas e programas de RH estão [...] considerando mais profundamente os aspectos culturais, os valores, as atitudes, as competências requeridas e as necessidades das organizações e seus colaboradores.

(Sigollo e Prestes Rosa, 2002)

A partir da década de 1970, com a crise do padrão de acumulação capitalista firmado no binômio taylorismo-fordismo, teve início o processo de substituição do modelo vigente por formas produtivas flexibilizadas, desreguladas e desregulamentadas. Como consequência, surgiu a necessidade de formular e de implantar novos modelos de gestão do trabalho:

o sistema flexível surgiu como uma possível resposta para superar essa rigidez. [...] As novas tecnologias permitem a transformação das linhas de montagem típicas da grande empresa em unidades de produção de fácil programação que podem atender às variações do mercado (flexibilidade do produto) e das transformações tecnológicas (flexibilidade do processo).

(Castells, 2005:211-212)

Para melhor enfrentar os desafios, as empresas passaram a investir em novas tecnologias, de base microeletrônica e adotaram modernas concepções organizacionais, reduzindo seus níveis hierárquicos e, utilizandose de inovações tecnológicas para garantir sua sobrevivência, com efeitos diretos na gestão do trabalho. Particularmente no setor público, fez-se indispensável a implantação de uma nova cultura organizacional com vistas à melhoria da gestão.

Nas duas últimas décadas, o processo de internacionalização da economia que estabeleceu novo padrão de relacionamento entre os países, aliado ao 
questionamento acerca do papel do Estado e às reformas políticas de desenho neoliberal, adotadas como solução para a crise econômica mediante a redução do aparato estatal com o objetivo de diminuir os gastos públicos, tiveram como consequência o desestímulo às políticas públicas efetivadas pelo estado de bem-estar social (welfare state).

No contexto de (re)ordenamento do mundo do trabalho, de (re)definição de questões de cunho social, político, econômico e cultural, algumas características sobressaem: o uso intensivo de inovações tecnológicas no sistema produtivo, a redução dos postos de trabalho, o desemprego estrutural, o aumento da exclusão social, a substituição do trabalho rotineiro e repetitivo por um trabalho que requer capacidade de análise, de decisão e de redirecionamento da ação em tempo real, em um nível que apenas o cérebro humano pode dominar. De acordo com Castells (2005): "todas as outras atividades são potencialmente susceptíveis de automação e, portanto, o trabalho nelas envolvido é dispensável".

Na dinâmica de crise da sociedade do trabalho ocorreu um fenômeno contraditório: a ampliação do desemprego e do trabalho precarizado e informal e, simultaneamente, a emergência de um trabalho revalorizado, no qual o trabalhador deve exercer, cada vez mais, funções abstratas e executar, cada vez menos, trabalho manual, de modo que a atividade estritamente laborativa se torna mais intelectualizada, complexa, autônoma e coletiva.

Assim, o trabalho não qualificado, fragmentado, repetitivo, rotineiro e prescrito, característico do modelo taylorista/fordista, nas instituições que adotaram novas formas de organização é substituído por um trabalho polivalente, integrado, em equipe, com mais flexibilidade e autonomia, o que exige maior capacidade de reflexão por parte do trabalhador. A excelência e a qualidade não estão na submissão do saber a um manual, nem na rigidez prescritiva e racionalidade tecnicista ou tecnocrática que limitam a criatividade do profissional. $\mathrm{O}$ trabalhador apoiado exclusivamente nos manuais de normas e procedimentos tornou-se anacrônico diante da nova realidade. Com o trabalho individualizado substituído pelo trabalho em grupo percebe-se a importância que as equipes de trabalho, gradativamente, foram adquirindo. Portanto, é possível dizer que as capacidades de diagnóstico e de solução de problemas, conjugadas com aptidões para tomar decisões, trabalhar em equipe, enfrentar situações em constantes mudanças e intervir para melhorar a qualidade dos processos, produtos e serviços, passaram a ser exigidas dos trabalhadores, diante das mudanças na natureza e no processo de trabalho. 


\section{Quadro 1 \\ O mundo do trabalho}

\begin{tabular}{|ll|}
\hline Perspectiva industrial (taylorismo/fordismo) & Perspectiva da sociedade do conhecimento \\
\hline Operador & Ator, reflexivo \\
Trabalho rotineiro, manual & Trabalho requer capacidades de análise, abstração e \\
& generalização \\
Executar o prescrito & Tomar iniciativas, atitudes \\
Executar ações & Executar açães/atenção a acontecimentos \\
Saber-fazer individualizado & Saber agir coletivamente \\
Esquemas elementares & Esquemas tecnológicos complexos \\
Rigidez no sistema de produção & Flexibilidade de produtos e processos \\
Gerenciamento pelo controle & Gerenciamento pela liderança \\
Repetição, previsibilidade & Inovação, imprevisibilidade \\
Simplicidade e não qualificação & Complexidade e competências \\
Exigência unidimensional & Exigência multidimensional, polivalência \\
\hline
\end{tabular}

A primeira e mais abrangente tendência de evolução organizacional identificada é a transição da produção em massa para a produção flexível, ou do fordismo ao pós-fordismo. [...] Quando a demanda de quantidade e qualidade tornou-se imprevisível; quando os mercados ficaram mundialmente diversificados e, portanto, difíceis de ser controlados; e quando o ritmo da transformação tecnológica tornou obsoletos os equipamentos de produção com objetivo único, o sistema de produção em massa ficou muito rígido e dispendioso para as características da nova economia.

(Castells, 2005:211-212)

O movimento de ajuste macroestrutural que, nas duas últimas décadas, vem atingindo o setor industrial também ocorreu no setor saúde. Embora a complexidade do trabalho em saúde pareça aproximar-se da produção industrial em alguns momentos, os dois setores têm focos diferentes e específicos. Essa compreensão possibilita o entendimento de como as mudanças no mundo do trabalho acontecem em função da reestruturação produtiva, da incorporação tecnológica, e como se processam as transformações humanas nessa nova relação. $\mathrm{O}$ trabalho em saúde guarda, porém, algumas características e especificidades singulares: é um trabalho reflexivo, em que as decisões a serem tomadas implicam a articulação de vários saberes que provêm de diferentes instâncias, razão pela qual não pode seguir uma lógica rígida como 
a da produção material de bens, sendo complexa sua normatização técnica e avaliação da produtividade.

No panorama de mudanças no processo de trabalho em saúde, com a constante introdução e utilização de inovações tecnológicas, consoante as novas formas de organização do trabalho em busca da melhoria da qualidade e da produtividade dos serviços, tornam-se imperativos a compreensão global do processo de trabalho, a maior articulação entre os diversos setores para o desenvolvimento de modelos de atenção voltados para a qualidade de vida, a maior integração das ações dos diferentes agentes que atuam na área da saúde, a comunicação entre os diferentes membros da equipe, a maior liberdade de decisão e autonomia para intervir no processo de trabalho. Assim, cabe apontar as diversas expressões da diferenciação do trabalhador coletivo em saúde quanto às suas formas de organização, seus diferentes graus de autonomia, suas distintas representações no imaginário social, suas formas de validação educacional e legal, além de seus estatutos corporativos. Vale ressaltar outro componente que é o elevado grau de divisão do trabalho observado na produção dos serviços de saúde e que tem resultado no aparecimento e na consolidação de novas categorias profissionais e ocupacionais, como consequência da expansão do desenvolvimento tecnológico. Nota-se, também, a importância das funções de delegar e descentralizar as ações no processo de trabalho. É fundamental, portanto, ampliar a qualificação dos trabalhadores, tanto na dimensão técnica especializada quanto na dimensão ético-política, comunicacional e de inter-relações pessoais, para que possam agir como sujeitos no mundo do trabalho (Santana, 1999; Deluiz, 2001).

\section{Quadro 2 \\ O trabalho em saúde}

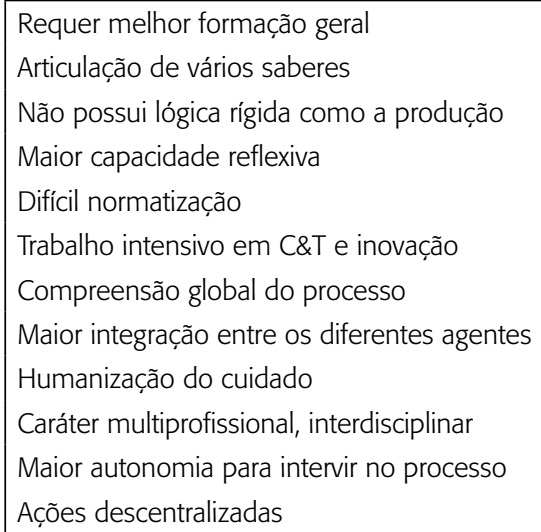




\section{Sobre as competências na saúde}

Diante de um mercado de trabalho complexo, instável, flexível e mutável, ampliam-se os requerimentos relativos às qualificações dos trabalhadores, tornando necessário instituir um modelo de formação e de gestão da força de trabalho baseado em competências profissionais - a gestão por competências $^{1}$ - que aparece como alternativa usualmente adotada pelas instituições, muitas delas utilizando o conceito de competência para direcionar suas ações estratégicas de recursos humanos com o objetivo principal de assegurar melhor qualidade e competitividade:

O aprofundamento da globalização das atividades capitalistas e a crescente busca de competitividade levaram ao alinhamento definitivo das políticas de recursos humanos às estratégias empresariais, incorporando à prática organizacional o conceito de competência, como base do modelo para se gerenciar pessoas, apontando para novos elementos na gestão do trabalho.

(Deluiz, 2001)

Para Fleury e Fleury (2000), o aumento da instabilidade política e econômica dos mercados e da competitividade global tem levado as empresas a relacionarem a formação de competências à definição da estratégia organizacional em uma tentativa de criar mais competência interna:

De um lado temos a organização, com um conjunto próprio de competências. Estas originam-se da gênese e do processo de desenvolvimento da organização e são concretizadas no seu patrimônio de conhecimentos.[...] De outro lado temos as pessoas, com seu conjunto de competências que pode ou não estar sendo aproveitado pela empresa. Organização e pessoas, lado a lado, propiciam um processo contínuo de troca de competências. A empresa transfere seu patrimônio para as pessoas, enriquecendo-as e preparando-as para enfrentar novas situações profissionais e pessoais, dentro ou fora da organização. As pessoas, por seu turno, ao desenvolver sua capacidade individual, transferem para a organização seu aprendizado, dando-lhe condições para enfrentar novos desafios.

(Dutra, 2001)

\footnotetext{
${ }^{1}$ É frequente na literatura sobre o assunto a utilização de expressões como "gestão baseada em competências", "gestão de pessoas baseada em competências", "gestão de desempenho baseada em competências" e "gestão de competências"; tais expressões, apesar das diferenças de ordem semântica, para este artigo representam a mesma ideia.
} 
Segundo essa abordagem, a organização define a sua estratégia e as competências necessárias para implementá-las, num processo de aprendizagem permanente. É por meio do processo de aprendizagem e de gestão do conhecimento que as organizações podem desenvolver as competências necessárias para a realização de sua estratégia competitiva.

\section{O conceito de competência}

Com relação às práticas de recursos humanos, variadas são as formas de utilização do termo competência. No entanto, é possível perceber a existência de duas fortes correntes de pensamento relacionadas à questão: uma representada, sobretudo, por autores franceses (Zarifian e Le Boterf, entre outros) e outra, por autores norte-americanos (McClelland e Boyatzis). A primeira entende a competência como as realizações da pessoa em determinado contexto, e a segunda associa o conceito a um estoque de qualificações (conhecimento, habilidades e atitudes) independente do contexto em que o indivíduo está situado.

O sentido de competência que emergiu na literatura francesa procurava ir além do conceito de qualificação, que estava restrito aos diplomas e aos códigos de profissões e vinculado "à escolarização e sua correspondência no trabalho assalariado, no qual o status social e profissional estava inscrito nos salários e no respeito simbólico atribuído a carreiras de longa duração" (Paiva, 2000). A crise da noção de "posto de trabalho", associado ao modelo de classificações e de relações profissionais fordistas, resultou na adoção de um modelo de organização do trabalho e de gestão da produção calcado nas competências e no desempenho individual dos trabalhadores. Está em curso, portanto, um processo de mudança cuja característica é a passagem da lógica centrada no posto de trabalho para outra, centrada nas competências do trabalhador. Nesse modelo, importa não só avaliar a posse dos saberes escolares ou técnico-profissionais, mas a capacidade de mobilizá-los para resolver problemas e enfrentar imprevistos em situação de trabalho. Os componentes não organizados da formação, como as qualificações tácitas ou sociais e a subjetividade do trabalhador assumem, no modelo das competências, extrema relevância (Deluiz, 1995).

No dizer de Zarifian (2001), "competência é a inteligência prática de situações que se apoiam sobre os conhecimentos adquiridos e os transformam com quanto mais força, quanto mais aumenta a complexidade das situações". 
Por sua vez, Carbone e colaboradores (2006) a consideram como "o desempenho expresso pela pessoa em determinado contexto, em termos de comportamentos e realizações decorrentes da mobilização e aplicação de conhecimentos, habilidades e atitudes no trabalho".

Em razão da atribuição que conferem, é possível classificar as competências em duas grandes categorias: as competências humanas, individuais ou profissionais e as competências organizacionais; a primeira relacionada a indivíduos ou a pequenas equipes de trabalho e a segunda a uma organização ou a uma de suas unidades produtivas.

Para Fleury e Fleury (2001), "competência é um saber agir responsável e reconhecido, que implica mobilizar, integrar, transferir conhecimentos, recursos e habilidades que agreguem valor econômico para a organização e valor social ao indivíduo".

Sob essa compreensão, a competência agrega, a um só tempo, valor econômico e social à organização e aos indivíduos, na medida em que contribui para a realização da estratégia organizacional e expressa o reconhecimento organizacional no tocante à capacidade do indivíduo.

Como visto, as interpretações e definições de "gestão por competências" e de "competências" são tão numerosas quanto diferentes entre si, revelando várias concepções na gestão de recursos humanos. No entanto, o conceito de competência tem sido utilizado para relacionar estratégia e processos de aprendizagem organizacional, e pode representar, tanto no plano teórico quanto no plano concreto das práticas gerenciais, uma reestruturação do campo da gestão de recursos humanos.

\section{Gestão de recursos humanos e estratégia organizacional}

A gestão por competências propõe-se a alinhar esforços para que as competências humanas possam gerar e sustentar as competências necessárias à consecução dos objetivos estratégicos de uma organização. A figura 1 ilustra as principais etapas (ou fases) de um modelo de gestão por competências e expõe a sua lógica de funcionamento.

Em resumo, é possível dizer que a gestão por competências objetiva gerenciar o gap de competências que eventualmente existe na organização, visando minimizá-lo. No entanto, a redução ou eliminação de eventuais gaps de competências está condicionada ao mapeamento das competências necessárias à consecução da estratégia organizacional. A utilização de modelos de gestão por competências impacta significativamente os principais subsistemas e processos de gestão de recursos humanos, como o planejamento, a avaliação de 
desempenho, a educação corporativa, a identificação e alocação de talentos, a orientação ao trabalhador visando a sua ascensão profissional, a melhoria da remuneração e a obtenção de benefícios, bem como a excelência e a qualidade do trabalho. Assim, a gestão por competências pode ser considerada um instrumento de mudança cultural e um meio de propiciar mais flexibilidade, adaptabilidade e espírito corporativo às instituições. Com a gestão por competências podem ser vinculados, por um lado, os principais objetivos de uma instituição e, por outro, o desenvolvimento de competências. Em órgãos públicos, pode-se adotar a gestão por competências como alternativa de gestão flexível e empreendedora que possibilite melhorar a qualidade e a eficiência dos serviços, incitando os trabalhadores do serviço público a desenvolver suas competências e, consequentemente, desenvolver as competências do governo em seu conjunto.

Figura 1

Modelo de gestão por competências

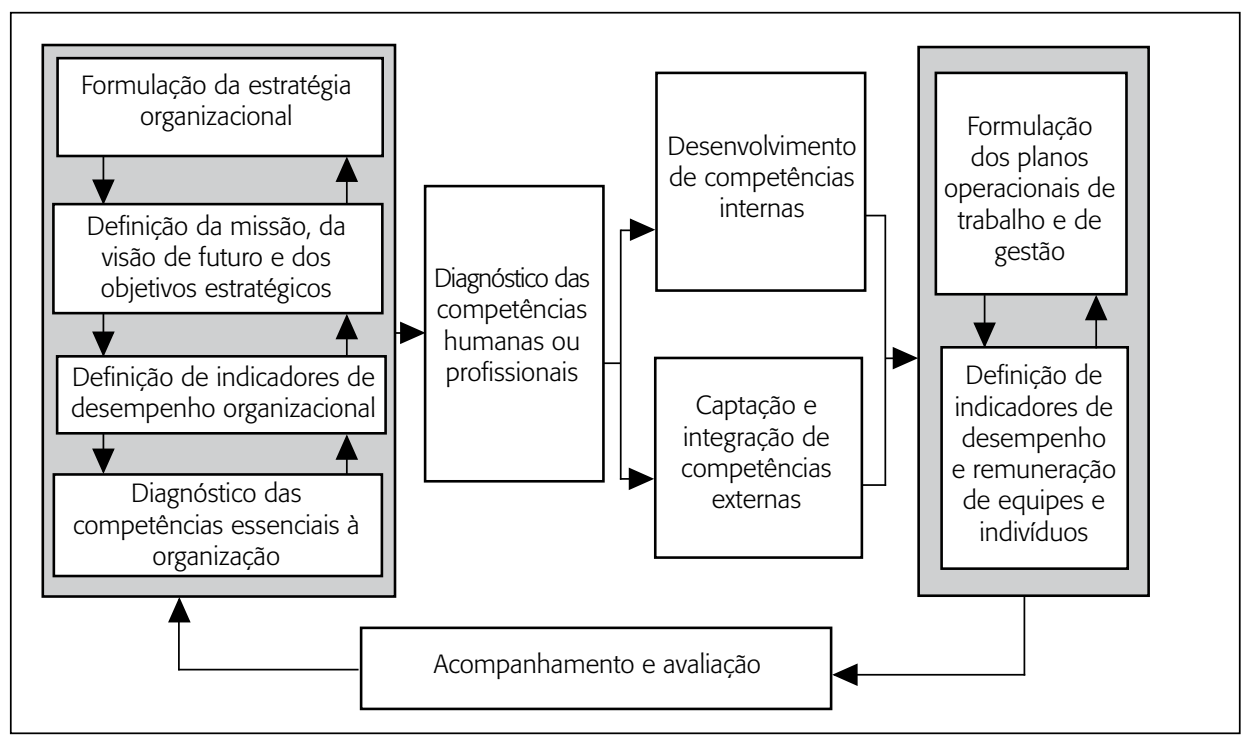

Fonte: Carbone et al. (2006).

\section{Do planejamento à gestão estratégica de recursos humanos}

A complexidade do mundo moderno, caracterizado por instabilidade e incertezas, obriga as empresas a se posicionarem com um mínimo de antecipação para enfrentarem esse ambiente de mudanças, o que torna vital o exercício gerencial de planejamento do empreendimento. Tal fato ocorre também nos 
órgãos públicos. Sistematicamente, as empresas estão adotando procedimentos de identificação de mudanças prospectivas e de tendências de mercados, previsão de necessidades de recursos e criação de novas maneiras de operar, tendo em vista os objetivos empresariais ou governamentais. Essa maneira de agir, que usualmente é denominada de "planejamento estratégico", vem sendo amplamente utilizada no mundo empresarial. Contudo, a literatura mostra que não há consenso, entre as organizações, em relação à definição de estratégia, dada à complexidade contida na expressão, cabendo a ele inúmeras definições, abordando diferentes aspectos.

Segundo Porter (1986), estratégia pode ser definida como a criação e o implemento de ações ofensivas e defensivas que uma empresa empreende em seu setor de atuação, para enfrentar, com sucesso, a concorrência de outras empresas, visando garantir sua competitividade e, assim, obter maior retorno sobre seus investimentos. Portanto, o planejamento estratégico é uma das ferramentas da administração para lidar satisfatoriamente com processos dinâmicos de mudança e transformações que, por sua vez, impõem mudanças nas organizações. Ele passou a ser utilizado a partir dos anos 1970, desenvolvido sob um processo deliberado do pensamento estratégico, ${ }^{2}$ no qual a técnica mais clássica era a análise de Swot. ${ }^{3}$

O planejamento estratégico pretende conhecer o ambiente interno para concentrar e direcionar as forças internas a uma organização, de maneira a que todos os seus funcionários trabalhem na mesma direção. Ademais, procura analisar o ambiente externo à organização e adaptá-la a ele, para que seja capaz de antever o futuro e agir proativamente, precavendo-se para reagir e enfrentar os desafios que forem surgindo. O objetivo é que a organização domine e conduza o processo de transformação e desenvolvimento, evitando ser envolvida e prejudicada por fatores externos, sobre os quais não tenha ingerência e controle. Isso não significa que o futuro possa ser previamente moldado, mas que a análise das mudanças e das possibilidades de adaptação aumenta a capacidade da organização para melhor lidar com eventuais crises que poderão surgir.

\footnotetext{
${ }^{2}$ Pensamento estratégico, segundo Lobato e colaboradores (2003:21), é o "sistema de levantamento e avaliação de situações com o objetivo de definir a estratégia da empresa e ao qual devem subordinar-se todas as suas decisões e operações".

${ }^{3}$ Tipo de análise baseada em forças, fraquezas, oportunidades e ameaças de uma organização. Essa técnica é baseada na avaliação do ambiente interno da empresa, mediante a análise de suas forças e fraquezas, e do ambiente externo, mediante suas oportunidades e ameaças.
} 
Para melhor compreender o planejamento estratégico, é importante não considerá-lo apenas um método ou uma técnica, mas um enfoque e uma perspectiva para lidar com situações complexas e processos de transformações acentuados e dinâmicos. Trata-se, então, de uma concepção que pressupõe um pensamento estratégico e que se desdobra na realização de ações concretas. É importante frisar que o planejamento estratégico representa um processo contínuo, permanente e cíclico.

Na década de 1980, ganhou importância a escola da administração estratégica, que trouxe como novidade a demonstração de que a implementação das estratégias é tão importante quanto a sua formulação, destacando o lado prescritivo do pensamento estratégico. Ansoff, ${ }^{4}$ um dos principais pensadores dessa escola, defendia a estratégia como um conjunto de regras de decisão para orientar o comportamento de uma organização.

Na década de 1990, assistiu-se à valorização da gestão estratégica, mediante um enfoque mais sistêmico do processo de planejamento e das funções estratégicas, visando estabelecer a integração de todos os setores da empresa, com a finalidade de melhor alocar os recursos para atingir os objetivos organizacionais. Um processo sistemático e constante de tomada de decisões, cujos efeitos deverão ocorrer em futuros períodos de tempo, composto de ações interdependentes e inter-relacionadas que visam ao alcance de objetivos estabelecidos.

Para efeito deste artigo, planejamento estratégico está sendo compreendido como a ação (ou conjunto de ações) realizada para que se defina a estratégia organizacional e gestão estratégica como o processo de ação gerencial, contínuo e sistemático, que visa assegurar à organização senso de direção e continuidade em longo prazo, assim como flexibilidade e agilidade cotidianas. ${ }^{5}$

\section{O planejamento estratégico de recursos humanos em saúde}

Na tentativa de relacionar planejamento estratégico e recursos humanos em saúde, Rovere (1993) destaca:

\footnotetext{
${ }^{4}$ Igor Ansoff, nascido em 1918 em Vladivostok (Rússia), foi professor e consultor norte-americano. Formou-se na Brown University em engenharia e matemática e trabalhou na Rand Corporation e, posteriormente, na Lockheed. É conhecido como o pai da gestão estratégica. Faleceu em 2002, em San Diego, Califórnia. Ansoff entendia a administração estratégica como um processo sistemático para a tomada de decisões, objetivando o sucesso da empresa em seu ambiente futuro.

${ }^{5}$ De acordo com Teixeira e colaboradores (2005), o planejamento estratégico pode ser uma das etapas da gestão estratégica.
} 
La planificación estratégica de recursos humanos em salud puede definirse o delimitarse como la planificación intencionada de intervenciones que diferentes instituciones, actores o fuerzas sociales realizan sobre el Proceso de desarollo de recursos humanos en salud, considerado como un objeto de transformación socialmente determinado. [...] En consecuencia, la Planificación Estratégica de Recursos Humanos en Salud debe ser un instrumento de transformación puesto al alcance de aquellos trabajadores de salud que, dispuestos a mudar de objetos a sujetos, son problematizados y problematizam una determinada realidad que deviene en objeto de transformación.

Em nossa realidade, ainda é incipiente a compreensão de que a área de recursos humanos deve atuar de forma proativa e empreendedora, antevendo e antecipando-se às mudanças e tendências de mercado, garantindo melhores resultados. O que se observa, na maioria das organizações, públicas ou privadas, é que persiste o modelo tradicional de gestão de recursos humanos (simbolizado nas atribuições de um "departamento de administração e controle de pessoal"), ou seja, ela não é percebida como uma questão estratégica, alinhada à missão da organização.

A gestão estratégica de recursos humanos representa importante iniciativa no sentido de estabelecer condições para promover o entendimento e a identificação dos indivíduos com a organização. Propicia adequação e coerência das políticas e práticas de recursos humanos aos objetivos estratégicos da organização, mediante o envolvimento e o comprometimento dos diferentes níveis hierárquicos da organização no processo de construção das ações para realização da missão institucional.

A gestão estratégica de recursos humanos não se restringe ao planejamento e controle da força de trabalho. Ela integra os recursos humanos aos objetivos da organização, por meio da implantação de um conjunto de diretrizes, políticas e ações. É possível afirmar que é uma importante etapa para propiciar a melhoria na gestão do trabalho em uma instituição, possibilitando transformar estratégias em ações. É uma ferramenta para dar suporte à relação contínua entre pessoas e instituição, agregando valor e podendo contribuir, decisiva e harmonicamente, no desenvolvimento da instituição e das pessoas que nela atuam.

\section{0 caso Fiocruz}

Este artigo foi elaborado tendo como referência os resultados de um estudo de caso, objetivando conhecer e analisar a gestão do trabalho em uma institui- 
ção pública de ciência e tecnologia aplicadas à saúde, procurando identificar a política e os procedimentos da incorporação e gestão da força de trabalho, bem como os preceitos de qualidade e excelência utilizados na gestão de $\mathrm{RH}$, buscando confrontar a teoria com a prática.

O estudo de caso permitiu observar, descrever e explorar aspectos de uma dada realidade, resultando em uma caracterização abrangente dos dados e na análise aprofundada de uma realidade em sua complexidade e em seu dinamismo próprio, reunindo informações relevantes para a tomada de decisão ou propostas de intervenção (todas elas em consonância com os princípios da Carta Iberoamericana de Qualidade na Gestão Pública ${ }^{6}$ e com os critérios do Modelo Iberoamericano de Excelência em Gestão ${ }^{7}$ ), visando modificar certas características ou maneiras de agir da instituição em relação à gestão de seus recursos humanos.

Além de levantamento bibliográfico sobre o assunto, foram utilizadas no estudo de caso várias fontes de dados, como entrevistas com gestores de recursos humanos da instituição enfocada, identificação e análise de documentos (leis, normas, regulamentos, pareceres, portarias, recomendações, relatórios gerenciais e registros históricos).

O estudo compreendeu quatro fases. A primeira consistiu em delimitar o local em que seria desenvolvido; a segunda foi de coleta de dados; a terceira foi a análise e interpretação dos dados e, a quarta, a redação do relatório e da proposta de melhorias como uma inovação gerencial institucional.

No desenvolvimento do estudo, adotou-se a abordagem qualitativa; no tocante à coleta e análise dos dados, foi utilizado roteiro de entrevista. A investigação buscou estabelecer o que era importante para os sujeitos que atuam no universo pesquisado. A Fiocruz foi escolhida como campo de estudo por ser uma instituição que, nos últimos anos, tem demonstrado interesse e envidado esforços para profissionalizar a gestão rumo à melhoria da qualidade dos serviços públicos prestados à população. Também pelo fato da sua força de

\footnotetext{
${ }^{6}$ A Carta Iberoamericana de Qualidade na Gestão Pública é um instrumento que serve como guia e orientação aos governos latino-americanos para alcançar a viabilidade de sistemas de qualidade e excelência.

${ }^{7}$ O Modelo Iberoamericano de Excelência na Gestão é um modelo supranacional que tenta criar um ponto de referência único no qual são refletidos os diferentes modelos de excelência nacional dos países latino-americanos. Este modelo é aplicável às empresas privadas e instituições públicas e serve para avaliar uma organização, estabelecer planos de progressos, identificar seus pontos fortes e setores para melhoria. Além disso, é uma fonte de informação para o desenvolvimento e planejamento estratégico.
} 
trabalho possuir perfil diversificado, possibilitando averiguar elementos para subsidiar uma proposta inovadora na gestão pública de recursos humanos em saúde no Brasil. O roteiro de entrevista semiestruturada foi elaborado visando compreender os procedimentos adotados pela instituição Fiocruz na área de recursos humanos, com a escolha dos entrevistados determinada pela posição ocupada em postos estratégicos da área de gestão da Fiocruz.

Com a finalidade de analisar os resultados obtidos a partir das entrevistas realizadas, foi adotado e utilizado o método do discurso do sujeito coletivo (DSC), de Lefèvre e Lefèvre (2005).

\section{A Fundação Oswaldo Cruz}

Vinculada ao Ministério da Saúde do Brasil, a Fundação Oswaldo Cruz (Fiocruz) é a mais destacada instituição de ciência e tecnologia em saúde da América Latina e a principal instituição não universitária de formação e qualificação de recursos humanos para o Sistema Único de Saúde e para a área de ciência e tecnologia em saúde no Brasil. Promover a saúde e o desenvolvimento social, gerar e difundir conhecimento científico e tecnológico, ser um agente da cidadania são conceitos que pautam a atuação dessa instituição em toda a sua trajetória.

A Fiocruz abriga atividades que incluem o desenvolvimento de pesquisas; a prestação de serviços hospitalares e ambulatoriais de referência em saúde, a fabricação de vacinas, de medicamentos, de reagentes e de kits diagnósticos, a informação e a comunicação em saúde, ciência e tecnologia, o controle de qualidade de produtos e de serviços em saúde, o ensino e a formação de recursos humanos. A Fiocruz está presente em todo o território brasileiro, seja mediante diferenciadas ações de suporte ao Sistema Único de Saúde, na formulação de estratégias de intervenção no campo da saúde pública, nas atividades de ensino e pesquisa, em expedições científicas ou na oferta de diversificados serviços e produtos. Tem por missão:

gerar, absorver e difundir conhecimentos científicos e tecnológicos em saúde pelo desenvolvimento integrado das atividades de pesquisa e desenvolvimento tecnológico, ensino, produção de bens, prestação de serviços de referência e informação, com a finalidade de proporcionar apoio estratégico ao Sistema Único de Saúde e contribuir para a melhoria da qualidade de vida da população e para o exercício pleno da cidadania.

(Fiocruz, 2005) 
Em dezembro de 2007, a Fiocruz possuía uma força de trabalho composta por 9.681 trabalhadores, somados servidores públicos, pessoal terceirizado, prestadores de serviço, com atividades em programas sociais e profissionais sob vínculos de fomento técnico e científico de caráter temporário. Destes, $4.202(43,4 \%)$ são servidores ativos permanentes e 5.479 (56,6 \%) são trabalhadores com outra modalidade de vínculo (figura 2):

\section{Figura 2}

\section{Distribuição da força de trabalho da Fiocruz, segundo vínculo trabalhista}

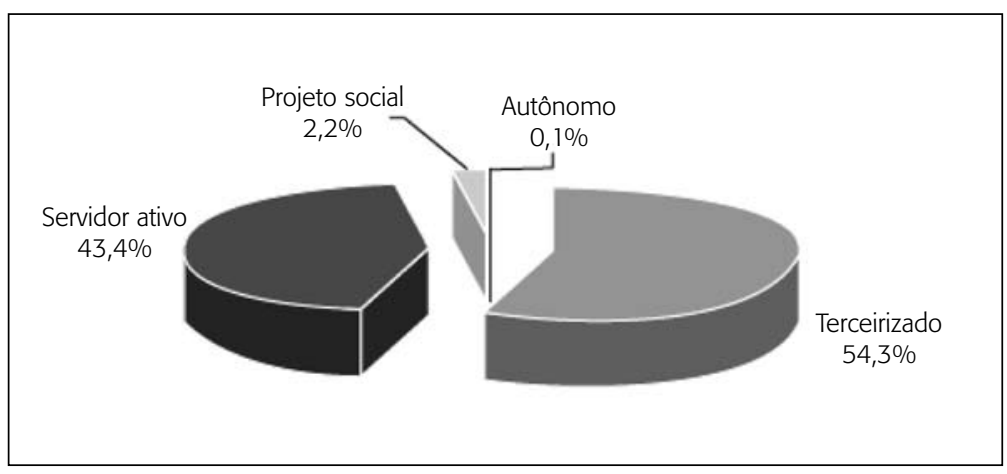

Fonte: Fiocruz (Relatório de Atividades, 2007).

Um desafio para a Fiocruz tem sido o de substituir gradativamente os postos de trabalho terceirizados por servidores do quadro permanente. Em função de um acórdão com o Tribunal de Contas da União (TCU), foram aprovadas 3 mil vagas para a Fiocruz, que seriam incorporadas até 2009. Assim, em 2006 realizou-se o maior concurso público da história da instituição, com 1.000 vagas para pesquisadores, tecnologistas, analistas e técnicos, que tinha por objetivo substituir igual número de trabalhadores com vínculos precários. Ainda em 2006, foi instituído o Plano de Carreiras e Cargos em Ciência, Tecnologia, Produção e Inovação em Saúde Pública da Fiocruz, que permitiu corrigir a situação da coexistência de cinco planos de cargos na instituição - cada um com mecanismos próprios de gestão, fortes discrepâncias salariais e iniquidade de direitos relativos a processos de titulação e qualificação. Além disso, o plano prevê drástica redução da força de trabalho precarizada existente na instituição, pela criação de 2.000 novas vagas, a serem preenchidas por meio de novos concursos públicos. 


\section{Resultados e discussão}

Do estudo realizado emergiram questões e procedimentos que sinalizam pontos frágeis na gestão do trabalho na Fiocruz, tais como: proporção elevada de profissionais não servidores; baixa definição, em termos de quantidade e de qualificação, do quadro de pessoal necessário para o cumprimento da missão institucional; carência de estudos em relação ao futuro da Fiocruz e que possibilitariam maior clareza e segurança para a tomada de decisões; ênfase no modelo de avaliação de desempenho com foco no incremento da remuneração pela via da gratificação, em detrimento da vinculação com o cumprimento de atividades finalísticas da instituição; ausência de um código de ética do servidor da Fiocruz e diversidade de formas de contratação de pessoal e de concessão de salários e de benefícios.

Entretanto, apesar das dificuldades existentes, é possível observar que a instituição vem desenvolvendo esforços significativos para fortalecer a área de recursos humanos, mediante a criação e a implementação de instrumentos de gestão participativa, tais como a Mesa de Negociação, a Câmara Técnica de Gestão do Trabalho, a Comissão Interna do Plano de Carreiras, envolvendo gestores e trabalhadores da instituição no processo de construção de referenciais e de indicadores para transformar a situação da força de trabalho da Fiocruz. Às medidas empreendidas no plano institucional, somam-se as ações realizadas pela Associação dos Servidores da Fundação Oswaldo Cruz (Asfoc) que, na defesa dos direitos e garantias dos seus associados, organiza movimentos políticos e sindicais, além de integrar instâncias coletivas institucionais de decisão.

Os debates, discussões e proposições, ocorridas no interior da instituição nos últimos anos, resultaram em um conjunto de diretrizes orientadoras das ações a serem desenvolvidas, expressas no Plano Quadrienal da Fiocruz 2005/2008, no item "Política da Fiocruz para a área da gestão do trabalho", entre as quais:

v aumentar o quadro de servidores pela via do concurso público e regular as outras formas de incorporação de profissionais, buscando assegurar a todos os trabalhadores, os mecanismos de proteção social garantidos em lei;

v valorizar o trabalhador que atua na instituição, independente do tipo de vínculo, zelando por sua qualidade de vida;

- considerar mecanismos de remuneração adicional alternativos ao adicional de titulação, para permitir que outras áreas, distintas das atividades de ensino e pesquisa, detenham condição equivalente de acréscimo remuneratório. 
Com respeito às propostas de ação, merecem ser realçadas:

- implantar um programa de desenvolvimento e gestão do trabalho que considere a diversidade de áreas de atuação da Fiocruz, as exigências da carreira em uma instituição pública de ciência e tecnologia aplicadas à saúde e que inclua um projeto de educação permanente e outro de acompanhamento e avaliação individual, compatível com indicadores de produtividade;

- estabelecer padrões e indicadores que orientem as indicações para os cargos comissionados e funções gratificadas, a partir de critérios como competência técnica para o exercício da função, experiência, dedicação, compromisso institucional, observando as peculiaridades de cada unidade que compõe a entidade;

- ampliar as ações de capacitação dos servidores, elevando o grau de titulação em todos os níveis de escolaridade, de acordo com as necessidades e demandas da instituição.

Conhecer as práticas da gestão de recursos humanos de uma instituição significa entender os mecanismos operacionais, administrativos e normativos relacionados às questões e às características do ambiente organizacional que interferem na sua implementação. Logo, é preciso considerar a diversidade de situações e graus de complexidade própria de cada instituição, incluindo o perfil profissional (formação) e tipos de vínculos dos trabalhadores que nela atuam.

As transformações que ocorrem no sistema capitalista e que influenciam na dinâmica e na configuração da sociedade ocidental, provocando marcantes mudanças nas relações e nos processos de trabalho, motivam a substituição do paradigma de "departamento de administração de pessoal" pela denominada "gestão estratégica de recursos humanos". No caso específico da Fiocruz, a questão dos recursos humanos é uma preocupação e uma iniciativa institucional relativamente recente, que vem se desenvolvendo de maneira lenta, procurando superar o padrão instituído e o estigma historicamente arraigado de "departamento de administração de pessoal", nem sempre com sucesso, seja devido à baixa compreensão, por parte do conjunto dos trabalhadores, da importância e da necessidade da decisão de que a instituição possua uma área de recursos humanos forte, influente, direcionada para as demandas atuais e futuras das atividades da instituição, seja por resistências internas, conjunturais, que dificultam os avanços. O estudo realizado, e que sustenta este artigo, mostra que hoje a questão dos recursos humanos na Fiocruz ainda é tratada de maneira bastante tradicional, com a limitada visão do ultrapassado "departamento de administração de pessoal". 
Assim, em relação aos esforços e incentivos de caráter institucional (como a criação do programa de capacitação profissional para o desenvolvimento institucional), ${ }^{8}$ observa-se, na Fiocruz, que a maioria das questões relacionadas a recursos humanos permanece com o caráter trabalhista e operacional. Percebese um divórcio entre o discurso idealizado, em que se classificam os recursos humanos como estratégicos e a prática organizacional, que ainda é eminentemente operacional, baseada em atividades tradicionais do antigo "departamento de administração de pessoal", de cunho mecanicista, taylorista e burocrático, não tratados como ativo estratégico organizacional. Ou seja: ainda está em gestão uma cultura institucional que prioriza o planejamento estratégico de recursos humanos, assumido como uma das formas de inovar a gestão.

Persiste, também, a necessidade de maior integração entre as políticas da Fundação Oswaldo Cruz e as do Ministério da Saúde, dada a sua inserção como instituição pública de suporte ao Sistema Único de Saúde e o compromisso em dar respostas às demandas do governo e da sociedade, objetivando a melhoria das condições. Fazer parte do Plano Plurianual ${ }^{9}$ do setor Saúde do governo federal constituiu um avanço para a Fiocruz, considerando o alinhamento do seu planejamento estratégico com as diretrizes políticas globais do governo federal.

\section{Considerações finais}

Diante de um contexto caracterizado por grandes transformações, vem ganhando adeptos um movimento no sentido de tornar imperiosa a formulação e a implantação de um modelo de formação e de gestão da força de trabalho baseado no enfoque das competências profissionais, figurando como alternativa mais viável para alinhar a política de recursos humanos às diretrizes e estratégias institucionais. É importante que sejam criados instrumentos de

\footnotetext{
${ }^{8}$ Uma das iniciativas do programa resultou na assinatura, em 2001, de convênio entre a Fundação Oswaldo Cruz (Fiocruz) e a Escola Nacional de Administração Pública (Enap) para realização dos seguintes cursos: Desenvolvimento para Gerentes Operacionais e Supervisores; Planejamento Estratégico: conceitos e ferramentas; Elaboração de Indicadores para o Desempenho Institucional e A Busca da Excelência no Atendimento ao Cidadão. O programa promoveu um relativo avanço nos debates sobre a importância de ações dessa natureza. A respeito do assunto, consultar Rodríguez (2004).

${ }^{9}$ O Plano Plurianual — previsto no art. 165 da Constituição Federal, e regulamentado pelo Decreto no 2.829 , de 29 de outubro de 1998 - estabelece as medidas, gastos e objetivos a serem seguidos pelo governo federal ao longo de um período de quatro anos.
} 
planejamento que deem subsídios à relação entre as pessoas e a instituição, os quais, simultaneamente, devem favorecer a integração da gestão de recursos humanos com as estratégias organizacionais.

Na prática organizacional da Fiocruz, o conceito de competência não é utilizado. Como instituição pública de ciência, tecnologia em saúde, ela poderia se beneficiar da gestão por competência como uma das ferramentas estratégicas de recursos humanos, tanto para o quadro de profissionais responsáveis diretos pela área de gestão propriamente dita, como para os que exercem suas funções no âmbito em que se cumprem as atividades finalísticas da instituição, pois existe boa receptividade por parte dos gestores ( $75 \%$ deles disseram conhecer a gestão por competência) quanto à possível utilização do modelo de gestão por competências.

Os resultados obtidos do estudo possibilitaram observar a ausência de indicadores de recursos humanos, não permitindo avaliações objetivas de desempenho em relação a ações, metas e resultados previamente fixados para aferir, também, o desempenho institucional. Ainda no tocante a esse tema, foi possível verificar a relação existente entre a gestão por competência e a gestão de desempenho, por ele expressar a competência de pessoas, de equipes e de organizações. Assim, é indicada a aplicação concomitante dessas duas ferramentas, visando direcionar esforços em torno de objetivos e metas organizacionais, mormente pelo fato de que a gestão por competências e a gestão de desempenho complementam-se num contexto mais amplo de gestão organizacional.

Quanto ao aspecto concurso, os realizados pela Fiocruz (1996, 1998, 2002 e 2006) ainda não ofereceram número de vagas suficiente para a consecução de sua missão institucional nem, tampouco, para substituir a totalidade da força de trabalho em situação precária.

É preciso ressaltar que, para concretizar uma gestão de recursos humanos coerente com a modernização institucional exigida pelos requerimentos de excelência e qualidade dos serviços prestados ao cidadão, tornase crucial instituir um sistema de incentivos (o que pode ser assegurado em plano de cargos e carreiras), atrelado a um processo de avaliação anual das atividades cumpridas bem como do potencial que cada profissional apresenta, podendo, inclusive, ser utilizadas técnicas empregadas no mercado de trabalho privado. Técnicas de promoção que valorizem a experiência profissional também podem ser aplicadas, como forma de reconhecer e de manter profissionais na instituição, em especial aqueles que, apesar de não possuírem titulação, são respeitados pelo notório saber em determinada área de conhecimento. 
Ainda considerando o caso específico da Fiocruz, alguns problemas relativos à questão dos recursos humanos que emergiram do estudo merecem destaque e aprofundamento, entre eles: existência de um movimento interno reativo a uma "cultura estratégica", facilitadora para a resolução de problemas identificados na gestão de recursos humanos; carência de diretrizes claras e transparentes para a área de recursos humanos; insuficiência de profissionais de recursos humanos devidamente qualificados; abordagem tradicional (e não estratégica) da temática de recursos humanos nas instâncias deliberativas da instituição, o que pode sugerir visão distorcida dos gestores quanto à apreciação e análise de temas da área; legislação exorbitante quanto às exigências inerentes aos processos administrativos e procedimentos operacionais de recursos humanos; e contratações não revestidas de planejamento associado a diretrizes institucionais.

Algumas recomendações podem ser assinaladas, discutidas e aprofundadas, visando contribuir para melhorar a qualidade da gestão institucional de recursos humanos. Mencione-se que, nessa perspectiva, sobressaem como importantes campos de análise, identificação de problemas e elaboração de propostas de intervenção, quando for o caso, as grandes áreas (ou eixos temáticos) compreendidas pela gestão estratégica e de recursos humanos, gestão por competência, mecanismos de avaliação de desempenho, ações de captação e de capacitação de recursos humanos e ações de políticas institucionais de recursos humanos. O estudo focado na Fiocruz teve como preocupação conhecer e apresentar considerações a respeito da gestão do trabalho na instituição, procurando descortinar alternativas para o seu aprimoramento e, além disso, abrir perspectivas na própria Fiocruz ou em outras instituições públicas, para o desenvolvimento de novos estudos a respeito do tema, a partir das questões abordadas.

Cabe ainda dizer que o diferencial que marcou o estudo não reside numa pretensa novidade ou no delineamento de práticas de recursos humanos nunca imaginadas ou inteiramente ausentes no cotidiano das instituições públicas. O diferencial está na compreensão e na articulação das práticas de recursos humanos à luz da gestão estratégica de recursos humanos em saúde e da gestão por competências. Ademais, foi esse o referencial teórico determinante das características metodológicas do estudo.

Por fim, espera-se que os resultados alcançados com este artigo possam ser uma contribuição valiosa para auxiliar a Fiocruz e o serviço público no campo da gestão de recursos humanos. Particularmente, ante sua posição no Sistema Único de Saúde e no Sistema Brasileiro de C\&T em Saúde, espera-se que, mediante maior qualificação e comprometimento de seus recursos huma- 
nos, o que decorre de uma melhor gestão, a Fiocruz possa ampliar seus espaços de atuação, colaborando mais incisivamente para a saúde da população brasileira.

\section{Referências}

CARBONE, P. P. et al. Gestão por competências e gestão do conhecimento. 2. ed. Rio de Janeiro: FGV, 2006.

CASTELLS, M. A sociedade em rede. 8. ed. São Paulo: Paz e Terra, 2005.

CLAD. Carta iberoamericana de calidad em la gestión pública. Aprovada pela X Conferência Iberoamericana de Ministros de Administração Pública e Reforma do Estado. El Salvador, 2008. Disponível em: <www.fundibeq.org/rutadeprogreso/ cartacalidad.pdf $>$. Acesso em: 24 jul. 2008.

DELUIZ, N. Formação do trabalhador: produtividade e cidadania. Rio de Janeiro: Shape, 1995.

. Qualificação, competências e certificação: visão do mundo do trabalho. In: Formação-humanizar cuidados de saúde: uma questão de competência, p. 5-14, Profae, Ministério da Saúde, 2001.

DEMO, Pedro. Educação profissional: desafio da competência humana para trabalhar. In: Educação profissional: o debate da(s) competência(s). Brasília: Ministério do Trabalho, Sefor, 1997.

DUTRA, J. S. Gestão por competências. São Paulo: Gente, 2001.

FIOCRUZ. Plano quadrienal 2005/2008, Rio de Janeiro, 2005. . Relatório de atividades - 2007, Rio de Janeiro, 2007.

FLEURY, A.; FLEURY, M. T. L. Estratégias empresariais e formação de competências. 2. ed. São Paulo, 2001.

FUNDIBEQ. Modelo iberoamericano de excelencia en la gestión. Fundação Iberoamericana para a Gestão da Qualidade. 2005. Disponível em: < www.fundibeq.org/DePortada/ AModelo.html>. Acesso em: 24 jul. 2008.

LEFÈVRE, Fernando; LEFÈVRE, Ana Maria, C. Discurso do sujeito coletivo: um novo enfoque em pesquisa qualitativa. 2. ed. Caxias do Sul/RS: Educs, 2005.

LOBATO, D. M. et al. Estratégia de empresas. Rio de Janeiro: FGV, 2003.

MELLO, M. L. B. C. Gestão estratégica de recursos humanos em uma instituição pública de ciência e tecnologia: o caso Fiocruz. 2007. Dissertação (Mestrado) — Es- 
cola Nacional de Saúde Pública Sergio Arouca, Fiocruz, Rio de Janeiro. Disponível em: < http://bvssp.cict.fiocruz.br/lildbi/docsonline/2/4/1042-mellomlbcm.pdf>. Acesso em: 15 set. 2007.

PAIVA, Vanilda. Qualificação, crise do trabalho assalariado e exclusão social. In: GENTILI, P.; FRIGOTTO, G. (Orgs.). A cidadania negada: políticas de exclusão na educação e no trabalho. Buenos Aires: Glacso, 2000.

PORTER, M. E. Estratégia competitiva: técnicas para análise de indústrias e da concorrência. Rio de Janeiro: Campus, 1986.

RAMOS, M. A pedagogia das competências: autonomia ou adaptação? São Paulo: Cortez, 2001.

RODRÍGUEZ, A. P. O. Capacitação de recursos humanos: o convênio Fiocruz-Enap e sua adequação às atividades finalísticas da instituição. 2004. Dissertação (Mestrado) — Escola Nacional de Saúde Pública Sergio Arouca, Rio de Janeiro, 2004.

ROVERE, M. R. Planificatión estratégica de recursos humanos en salud. Washington, D. C.: OPS, 1993.

SANTANA, J. P. A gestão do trabalho nos estabelecimentos de saúde: elementos para uma proposta. In: PARANAGUA, J. P. (Org.). Cadrhus. EDUFRN/Natal, 1999.

SIGOLLO; W.; PRESTES ROSA; L. E. Introdução. In: BOOG, G.; BLOOG, M. (Orgs.). Manual de Gestão de Pessoas e Equipes, FEA/USP. São Paulo: Gente, 2002.

TEIXEIRA; G. M. et al. Gestão estratégica de pessoas. Rio de Janeiro: FGV, 2005.

ZARIFIAN, P. Objetivo competência: por uma nova lógica. São Paulo: Atlas, 2001. 